\title{
Generation and Characterization of Human Cryptorchid-Specific Induced Pluripotent Stem Cells from Urine
}

\author{
Junmei Zhou, ${ }^{1}$ Xue Wang, ${ }^{2}$ Shengli Zhang, ${ }^{2}$ Yijun Gu, ${ }^{1}$ Ling Yu, ${ }^{2}$ Jing Wu, ${ }^{1}$ Tongbin Gao, ${ }^{2}$ and Fang Chen ${ }^{2}$
}

Cryptorchidism is a common congenital birth defect in human beings with the possible complication of infertility. An in vitro model of cryptorchidism might be valuable due to the inaccessibility of human embryos for research purposes. In this study, we reprogrammed urine cells containing genetic variations in insulin-like factor 3, zinc finger (ZNF) 214, and ZNF215 from a cryptorchid patient by introducing human OCT4, SOX2, C-MYC, and KLF4 with lentivirus. The cells were then replated on irradiated mouse embryonic fibroblasts and cultured with the human embryonic stem (ES) cell medium. The compact colonies with well-defined borders were manually picked, and 2 induced pluripotent cell lines were fully characterized. Our results demonstrated that these 2 cell lines were similar to human ES cells in morphological appearance, marker expression, and epigenetic status of the pluripotent cell-specific gene, OCT4. These cells could be differentiated into cells of all 3 germ layers in teratomas and in vitro, including into the VASA-positive germ cell lineage. Both parental urine cells and the reprogrammed cells possessed the normal karyotype and the same short tandem repeat loci, indicating that these 2 cell population share the same genetic identity. This establishment and characterization of human urinederived cryptorchid-specific induced pluripotent stem cells could present a good human genetic system for future studies investigating the molecular mechanism of cryptorchidism.

\section{Introduction}

C RYPTORCHIDISM IS ONE OF the most common congenital birth defects in newborn boys, and it involves multifactorial influences, including genetic mutations and environmental factors [1,2]. The unilateral or bilateral undescended testis may be located between the abdominal cavity and the top of the scrotum. One serious complication of cryptorchidism, especially in bilateral cases, is male infertility [3]. The underlying genetic causes and mechanisms of cryptorchidism-related male infertility remain unknown because of the inaccessibility of early human embryos for research purposes and the ethical debate surrounding the genetic manipulation of human embryos. Therefore, establishing an in vitro human model could provide an alternative for investigating testicular function and cryptorchidism-related male infertility.

Recent advances in cell biology have enabled the establishment of such a model [4]. Human induced pluripotent stem (iPS) cells could be an appropriate in vitro model of the early development of human embryos. iPS cells were derived by introducing a set of critical transcription factors into the somatic cells and reprogramming them into pluripotency [57]. These cells had the critical characteristics of self-renewal and pluripotency in common with human embryonic stem (ES) cells [8]. iPS cells could provide histocompatible cells for transplantation medicine, but could also serve as an in vitro disease model for the investigation of the corresponding disease mechanism [9]. In addition, human ES cells and iPS cells with normal genetic backgrounds have been induced to the germ cell lineage, which could be used to imitate early gonadal development and provide an alternative in vitro model to investigate germ cell determination and differentiation. However, no human iPS cell lines with a reproductive genetic background have been established thus far.

In this study, we have reprogrammed urine cells containing genetic variations in insulin-like factor 3 (INSL3), zinc finger (ZNF) 214, and ZNF215 from a cryptorchid patient by introducing human OCT4, SOX2, C-MYC, and KLF4 with a lentivirus. Compared with the human ES cell line $\times 01$ (kindly provided by Dr Xiao of Shanghai Institutes for Biological Sciences), the pluripotency of the reprogrammed cells was fully demonstrated by differentiation into cell types of all 3 germ layers. This human genetic system could be applied to explore germ cell determination and differentiation in future research.

\section{Materials and Methods}

\section{Primary culture of urine cells}

This research was approved by the Ethics Review Board of the Children's Hospital of Shanghai, and written informed

\footnotetext{
${ }^{1}$ Central Laboratory, Children's Hospital of Shanghai, Shanghai Jiaotong University, Shanghai, China.

${ }^{2}$ Department of Urology, Children's Hospital of Shanghai, Shanghai Jiaotong University, Shanghai, China.
} 
A

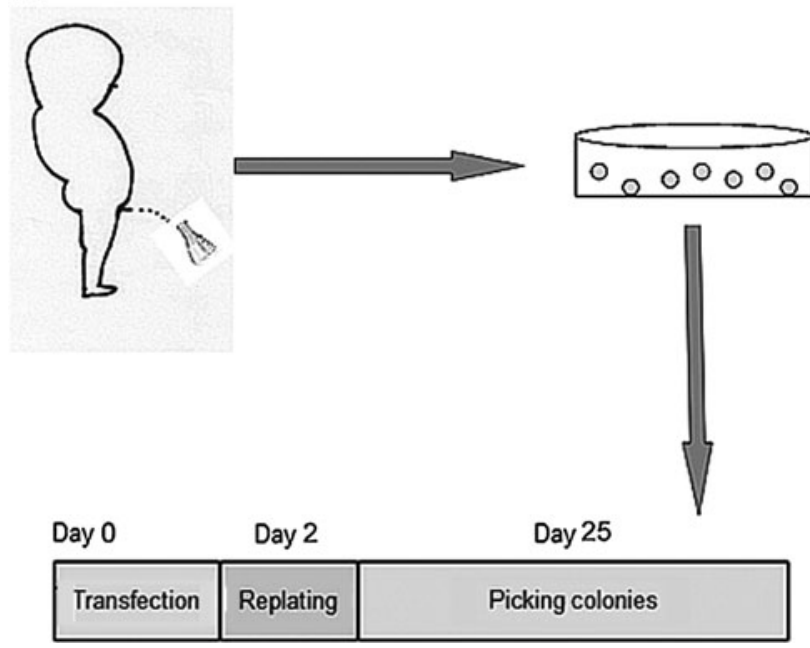

B

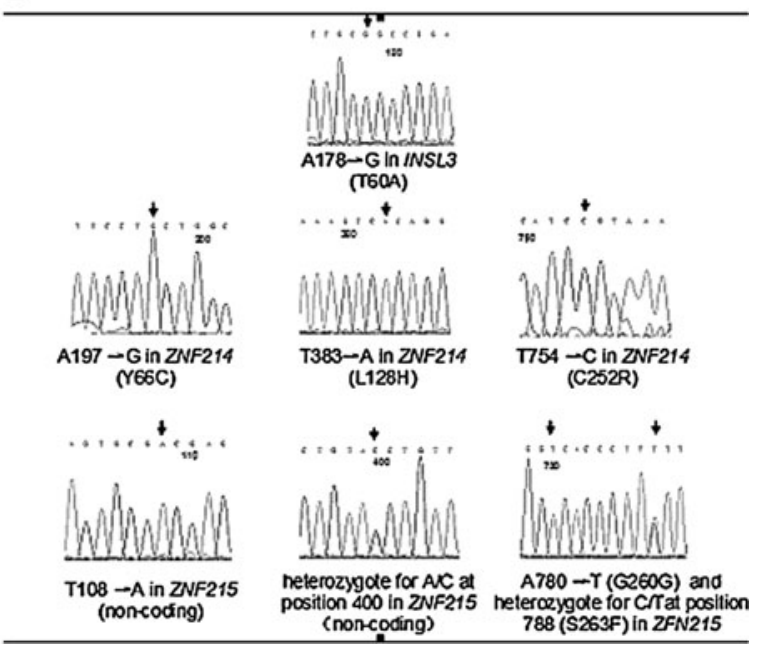

FIG. 1. Derivation of induced pluripotent stem (iPS) cells from urine cells and the detection of the genetic mutations. (A) A schematic diagram of iPS cell generation. (B) Seven mutations were detected in the exons of the insulin-like factor 3 (INSL3), zinc finger (ZNF) 214, and ZNF215 genes.

consent form was obtained from the patients. Urine cells were cultured and generally characterized according to our previous report [10]. Briefly, $200 \mathrm{~mL}$ of fresh urine were collected and centrifuged at $1000 \mathrm{rpm}$ for $15 \mathrm{~min}$. The pellets were then resuspended in a culture medium and plated in a 24-well culture plate. Five days after cell seeding, the medium was changed for the first time. After that, the medium was changed every 2 days. Cells with short spindle morphologies were passaged at confluence, and then used for the subsequent reprogramming experiment. The culture medium was a 1:1 mixture of medium $\mathrm{A}$ and medium B. The medium A was composed of keratinocyte serum free medium (KSFM) supplemented with $5 \mathrm{ng} / \mathrm{mL}$ epidermal growth factor, $50 \mathrm{ng} / \mathrm{mL} \mathrm{BPE}, 1 \% \mathrm{P} / \mathrm{S}$, and $1 \%$ L-glutamine. The medium B was composed of $3 / 4$ Dulbecco's modification of Eagle's medium (DMEM) (high glucose), 1/4 F-12 Ham's medium, 10\% fetal bovine serum (FBS), $0.4 \mu \mathrm{g} / \mathrm{mL}$ hydrocortisone, $10 \mathrm{ng} / \mathrm{mL}$, insulin, $5 \mu \mathrm{g}$ / $\mathrm{mL}$ transferrin, $1 \% \mathrm{P} / \mathrm{S}$, and $1 \%$ L-glutamine. A schematic of the reprogramming protocol is shown in Figure 1A.

\section{Sequencing of genetic mutations}

Genomic DNA was extracted from the peripheral blood of patients using the TIANamp Blood DNA Kit (Tiangen Biotech) according to the manufacturer's instructions. All of the exons of INSL3, ZNF214, ZNF215, and exon 8 of LGR8 were amplified from the genomic DNA using the TaKaRa rTaq kit (Takara) with the primers listed in Table 1 . Sequence data were analyzed against the respective reference sequences from the National Center for Biotechnology Information database. All these experiments were repeated 3 times.

\section{Derivation of iPS cells from urine cells}

Human cDNAs for OCT4, SOX2, C-MYC, and KLF4 were cloned into the Lv-ef1a-MCS-IRES-EGFP vector, lentiviruses were packaged in $293 \mathrm{~T}$ cells, and then $1 \times 10^{5}$ urine cells were infected with lentiviruses expressing OCT4, SOX2, C-MYC, and KLF4. Cells were then collected, replated on irradiated mouse embryonic fibroblasts (MEF), and fed with the human ES medium, which was changed daily [8]. Colonies with a

Table 1. Primers Set for Detection of Mutation

\begin{tabular}{lrll}
\hline Gene & Exon & \multicolumn{1}{c}{ Forward primers } & \multicolumn{1}{c}{ Reverse primers } \\
INSL3 & 1 & TGGGAGAAAGGCTCTGGCAC & CTGGGCACATGCATGCAAAC \\
RXFP2 & 2 & TGCATGCATGAGTGTTTGGTGGG & ATCAGTAGGGACAGAGGGTC \\
ZNF214 & 8 & GGGGAGGCAGGTTTATTTC & AAGCTAGTGCTAGATGTCATTGC \\
& 1 & GGGATACTTCTGGCCAATCA & TCCGTTGCTTATCCAGATCC \\
& 2 & TTCGGCTTGCCACATATCTT & TGTCCTGGAATCTGTCTTGCT \\
ZNF215 & $3 \mathrm{a}$ & GCTTTTATCTCACCATGGGATT & TGGCTGAAGCTCTTACCACA \\
& $3 \mathrm{~b}$ & AGCTCCGGAGTTCACTTTCA & TGTTGCTTGGGATTACTTGTG \\
& 1 & GAACAGAAAGGCGATTTGGA & ACGAGAACGATACCCGTGAG \\
& 2 & CCCTCCGTCACAGTGGTACT & AGCTCCTGATAGGCAATGGA \\
& 3 & TTTGTCCTTTGGGAAACTGG & CACTTGATACTCTCTGGCCTCA \\
& 4 & GGCCTGACCTTTGAAGATTG & CCAGTGTCCTGTGGGAAAAT \\
& 7 & TGGCTCCTACCCTATTCCTTC & TTGGGTGCACATTGTCTGT \\
& GCCTCCATTTCCTATTGAAGC & GTTCTGCATTCTGACTGAAGGT \\
\hline
\end{tabular}

INSL3, insulin-like factor 3; ZNF, zinc finger. 
compact appearance were manually picked at $\sim 25$ days after infection and expanded routinely as human ES cells for further characterization.

\section{Alkaline phosphatase staining and immunocytochemistry}

Cells were fixed in $4 \%$ paraformaldehyde for $15 \mathrm{~min}$. Alkaline phosphatase (AP) staining was carried out according to the manufacturer's recommendations (Millipore). For immunocytochemistry, cells were permeabilized with $0.2 \%$ Triton X-100 at room temperature for $20 \mathrm{~min}$, blocked in 3\% bovine serum albumin for $20 \mathrm{~min}$, and then incubated with a primary antibody overnight at $4^{\circ} \mathrm{C}(O C T 4$, NANOG SSEA-3, SSEA-4, TRA 1-60, and TRA 1-81 antibodies were obtained from Millipore, AE1/3 from DAKO and UPK3 from Abcam). Then, the cells were washed and incubated with a Cy3-conjugated secondary antibody (Jackson Labs) for $2 \mathrm{~h}$ at room temperature. The cell nuclei were counterstained with Hoechst 33258 (Sigma) and sealed with an antifade reagent (Gibco, Invitrogen). Images of the stained cells were taken with an Olympus fluorescent microscope.

\section{Karyotype analysis of urine cells and reprogrammed cells}

The cells were incubated in a medium supplemented with $0.1 \mathrm{mg} / \mathrm{mL}$ colchicine for $3 \mathrm{~h}$ at $37^{\circ} \mathrm{C}, 5 \% \mathrm{CO}_{2}$. The cells were then trypsinized, hypotonically treated in $75 \mathrm{mM} \mathrm{KCl}$, and fixed in cool methanol:acetic acid (3:1). The cell suspensions were spread on clean, ice cold microscope slides. The chromosomes were stained with 5\% Giemsa for $20 \mathrm{~min}$ and observed at $1,000 \times$ magnification.

\section{In vitro and in vivo differentiation of reprogrammed cells}

For in vitro differentiation, reprogrammed cells were detached from feeders and cultured in suspension to form embryonic bodies (EBs). The medium was composed of $80 \%$ DMEM and 20\% FBS (Gibco, Invitrogen). After 12 days, the
EBs were collected and replated on gelatin-coated culture dishes for further differentiation. The EBs usually attached to the culture dish on the second day, and the differentiation medium was changed every other day.

For in vivo differentiation, $2-3 \times 10^{6}$ reprogrammed cells were intramuscularly injected into 6- to 8-week-old immunedeficient NOD/SCID mice. The mice were observed 8 weeks after injection and euthanized to dissect the teratomas. The teratomas were embedded in paraffin, sectioned, and stained with hematoxylin-eosin.

\section{Gene expression analysis of reprogrammed cells}

Total RNA was extracted using the TRIzol reagent (Invitrogen), and the cDNA was synthesized with M-MLV reverse transcriptase (Takara) according to the manufacturer's protocols. Quantitative real-time polymerase chain reaction (PCR) was performed with SYBR Green Master MiX (Takara) in an ABI 7500 machine. Table 2 lists the primers of genes representing the 3 embryonic germ layers as well as the total and endogenous genes. PCR reactions were performed in triplicate, and gene expression was normalized to the housekeeping gene GAPDH.

\section{Bisulfite genomic sequencing}

Bisulfite treatments were performed using the Cp Genome modification kit (Chemicon) according to the manufacturer's instructions. PCR primers of the human OCT4 promoter are listed in Table 2. Amplified PCR products were cloned into the pMD18T - Easy vector, and at least 10 randomly selected clones were sequenced and analyzed.

\section{STR analysis}

DNA was extracted using a Genomic DNA Purification kit (Sigma), amplified with the Goldeneye ${ }^{\mathrm{TM}} 16 \mathrm{~A}$ short tandem repeat (STR) kit (Dingsheng High Technology, Inc.) according the manufacturer's instructions, and then analyzed on an ABI 3100 genetic analyzer.

Table 2. Primers Set for the Characterization of Parental Cells and Reprogrammed Cells

\begin{tabular}{|c|c|c|}
\hline Gene & Forward primers & Reverse primers \\
\hline UPK1A & ACGTCCTACACCCACCGTGA & ACCCCACGTGTAGCTGTCGAT \\
\hline CK7 & TGGTGCTGAAGAAGGATGTG & CACGCTGGTTCTTGATGTTG \\
\hline$\alpha-S M A$ & GGGCTCTGTAAGGCCGGCTT & CGTGAGCAGGGTGGGATGCTC \\
\hline NESTIN & GAGGACCAGAGTATTGTGAGAC & CACAGTGGTGCTTGAGTTTC \\
\hline$N F$ & ACCCGACTCAGTTTCACCA & ТТСТТСАССТТСАССТССТТС \\
\hline BMP4 & TTTGTTCAAGATTGGCTGTC & AGATCCCGCATGTAGTCC \\
\hline MYOGLOBIN & GCCACCAAGCACAAGATC & CTGCССАССТСТАСТАААСА \\
\hline GATA4 & CССAATCTCGATATGTTTGACG & CGTTTTCTGGTTTGGATCCC \\
\hline$A F P$ & CTTTGGGCTGCTCGCTATGA & TGGCTTGGAAAGTTCGGGTC \\
\hline OCT4 (endo) & GGGAGGAGCTAGGGAAAGAAAACCT & GAACTTCAССТTСССТССАAССАGT \\
\hline OCT4 (total) & AGAAGGATGTGGTCCGAGTGTG & CCACССTTTGTGTTCССАATTCC \\
\hline SOX2 (endo) & TTAGAGCTAGTCTCCAAGCGACGA & CCACAGAGATGGTTCGCCAG \\
\hline SOX2 (total) & CGCCCCCAGCAGACTTCACA & СТССТСТTTTGCACСССТСССАТTT \\
\hline NANOG & TGAACCTCAGCTACAAACAGGTG & AACTGCATGCAGGACTGCAGAG \\
\hline LIN28 & CAGGTGCTACAACTGTGGAG & GCACССТАТТСССАСТTТСТСС \\
\hline CRIPTO & TACCTGGCCTTCAGAGATGACA & CCAGCATTTACACAGGGAACAC \\
\hline FGF4 & CTACAACGCCTACGAGTCCTACA & GTTGCACCAGAAAAGTCAGAGTTG \\
\hline ESG1 & ATATCCCGCCGTGGGTGAAAGTTC & ACTCAGCCATGGACTGGAGCATCC \\
\hline OCT4-OF & TTTGTTTTTTGGGTAGTTAAAGG & СТТСТСАТТАСАААСТССАААСТС \\
\hline OCT4-IF & GGTAGATTTGTGGTAGGTATTGA & СТТСТСАТТАСАААСТССАААСТС \\
\hline
\end{tabular}


FIG. 2. Cultivation and characterization of urine cells. (A) Large, round urine cells could not be continuously propagated. (B) Small urine cells with a spindlelike appearance were able to continuously propagate. These cells were negative for OCT4 and SOX2 and positive for UPK1A, CK7, and $\alpha$ smooth muscle actin (C) These cells expressed AE1/3 (D) and UPK3 (E) and did not express OCT4 (F). Magnifications: $400 \times$ for A and B; $200 \times$ for D, E, and F.
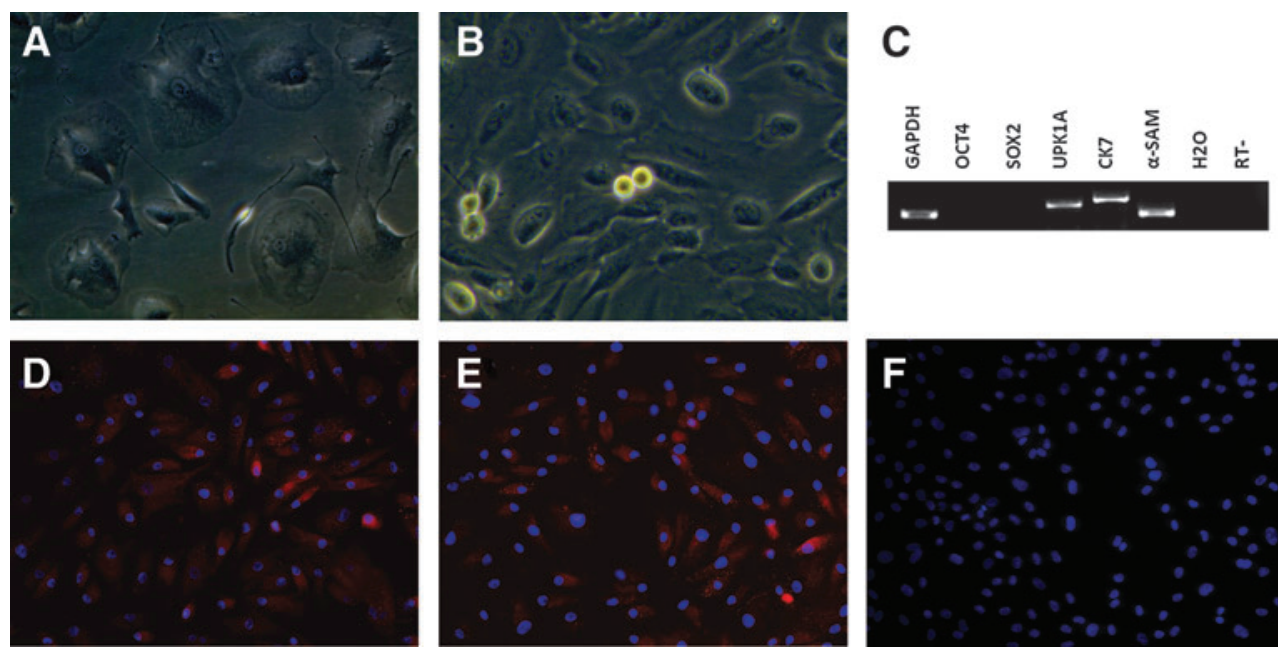

\section{Results}

\section{Detection of genomic variations}

We detected 6 homozygous and 2 heterozygous nucleotide sequence variations, including 1 in INSL3, 3 in ZNF214, and 4 in ZNF215 (Fig. 1B). Among these variations, 6 (c.A197>G, c.T383>A and c.T754>C in ZNF214; c.T108 > A, c.A400 > C and c.A780 > T in ZNF215) had been previously reported, whereas 2 represented novel findings. One novel variation was in exon 1 of INSL3 (c.A178 $>$ G),
FIG. 3. Sequential morphological changes from urine cells to reprogrammed cell colonies. (A) Urine cells were flat, short, and spindleshaped with some cell splitting observed under high magnification (B). (C) Approximately 17 days after transfection and replating on mitomycin-C inactivated MEF, compact small cell clusters formed. The small, compact clusters were manually picked 25 days after transfection, propagated on MEF, and fed with human ESM. Typical human ES-like colonies formed (D), which were AP-positive (E) with a high nucleus-to-cytoplasm ratio (F) Magnifications: $100 \times$ for A, C, D, and E; $200 \times$ for B; $400 \times$ for $\mathbf{F}$. MEF, mouse embryonic fibroblasts; ES, embryonic stem; ESM, embryonic stem cell medium; $\mathrm{AP}$, alkaline phosphatase.
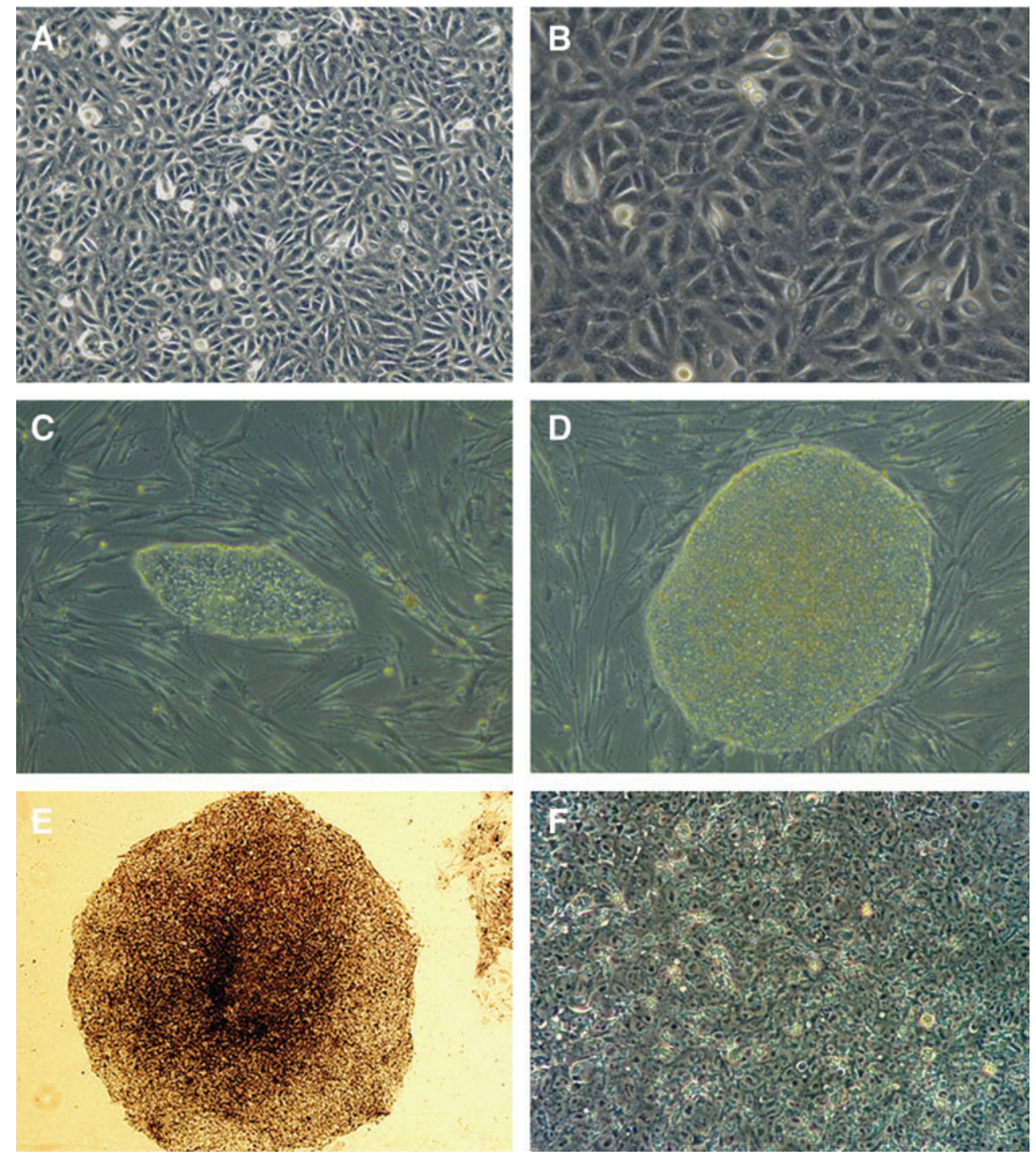
which changed amino acid 60 from threonine to alanine (T60A); the other was in exon 7 of ZNF215 (c.C788>T), which changed amino acid 263 from serine to phenylalanine (S263F).

\section{In vitro propagation and characterization of urine cells}

Approximately 8 days after seeding, cells were observed at the bottom of a culture dish. These cells mainly had 1 of 2 different morphologies: large round cells (Fig. 2A) or much smaller and spindle-like cells (Fig. 2B). Only the latter cells were able to propagate continuously throughout the duration of the experiment. Reverse transcription-polymerase chain reaction (RT-PCR) indicated that these cells were negative for OCT4 and SOX2, while they were positive for $U P K 1 A, C K 7$, and $\alpha-S M A$ (Fig. 2C). Immunostaining experiments indicated that these cells were immuno-positive for $A E 1 / 3$ (Fig. 2D) and UPK3 (Fig. 2E) and immunonegative for OCT4 (Fig. 2F).

\section{Reprogrammed cells are morphologically similar to human ES cells}

Cells displayed sequential morphological changes during the reprogramming process (Fig. 3). The original cells grew as a monolayer as cell division observed (Fig. 3A, B). Seven to eight days after the cells were replated on MEF, small cell clusters appeared and became progressively larger each day. On day 17, the compact colonies formed (Fig. 3C). These colonies were manually picked on day 25 postinfection. These human ES-like cells could be expanded on MEF feeder cells. After continuous passaging, the colonies were large and round with defined boundaries (Fig. 3D). These colonies were positive for AP (Fig. 3E) and had a high nucleusto-cytoplasm ratio under high magnification (Fig. $3 F$ ).

In 3 independent experiments, we obtained 12 colonies from $1 \times 10^{5}$ parental urine cells. Six AP-positive colonies were picked, and 2 iPS cell lines, named Cryp-iPS 20-1 and Cryp-iPS 20-3, were fully characterized.

\section{Reprogrammed cells express human ES cell-specific marker proteins}

Like the human ES cell line $\times 01$, the Cryp-iPS 20-1 and Cryp-iPS 20-3 cell lines established here expressed human ES cell-specific marker proteins, including OCT4, SOX2, NANOG, stage-specific embryonic antigen (SSEA)-4, TRA-1-60, and TRA-1-81 (Fig. 4).

\section{Gene expression and methylation analysis of reprogrammed cells}

Quantitative PCR indicated that endogenous OCT4 and SOX2 were fully induced by reprogramming (Fig. 5A). RTPCR revealed that Cryp-iPS 20-1 and 20-3 expressed many markers of pluripotency at levels comparable to those in $\times 01$ human ES cells, including OCT4 (endogenous), SOX2 (endogenous), NANOG, CRIPTO, FOXD3, LIN28, ESG1, and FGF4 (Fig. 5B). In contrast, those genes were expressed at almost undetectable levels in parental urine cells (Fig. 5B).

Bisulfite genomic sequencing indicated that Cryp-iPS 20-1 and 20-3 cell lines were highly unmethylated, similar to the human ES cell line $\times 01$, whereas the same region was highly methylated in urine cells (Fig. 5C). This result is in accordance with the RT-PCR and quantitative PCR results, which indicate that endogenous OCT4 is active in Cryp-iPS 20-1 and 20-3.

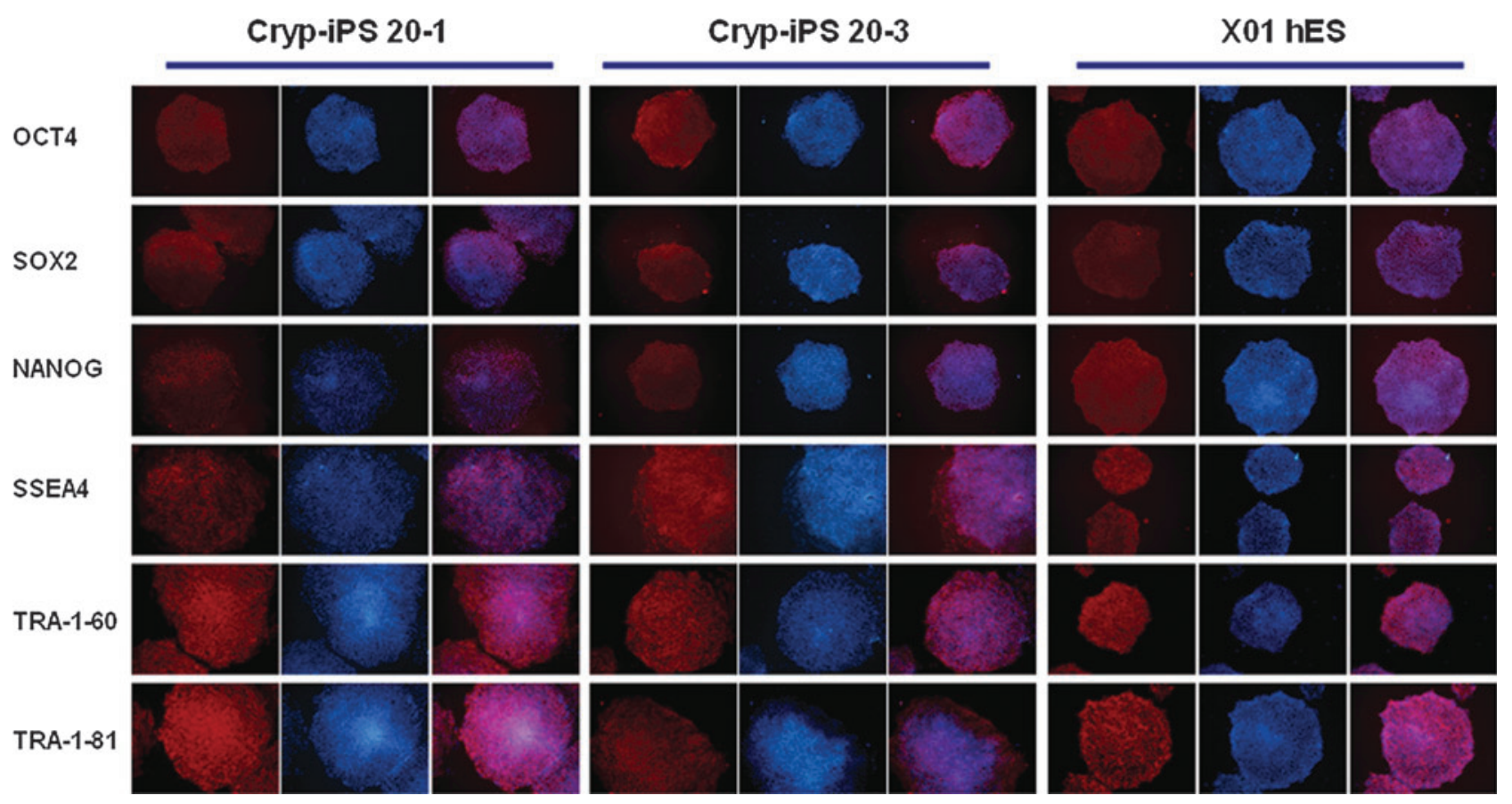

FIG. 4. Immunostaining of Cryp-iPS cells using antibodies against OCT4, SOX2, NANOG, SSEA4, TRA-1-60, and TRA-1-81. Cryp-iPS 20-1 (left) and Cryp-iPS 20-3 cells (middle) expressed the same markers as the human ES cell line $\times 01$ (right). All images are $100 \times$ magnification. 
A
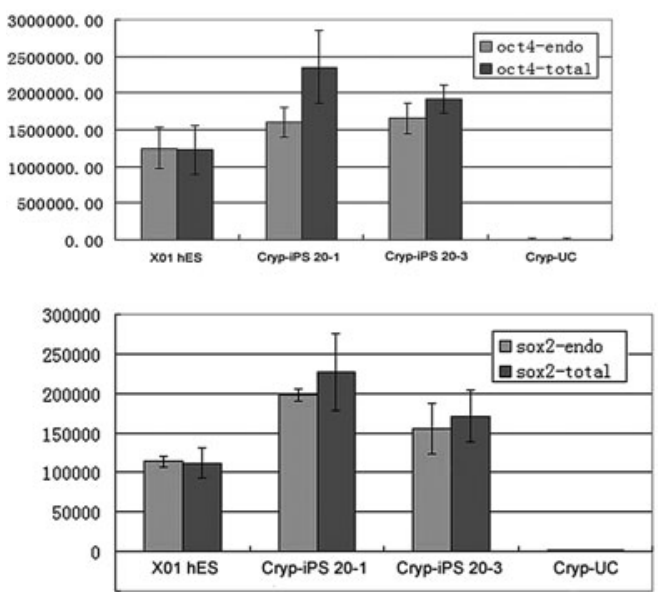

B

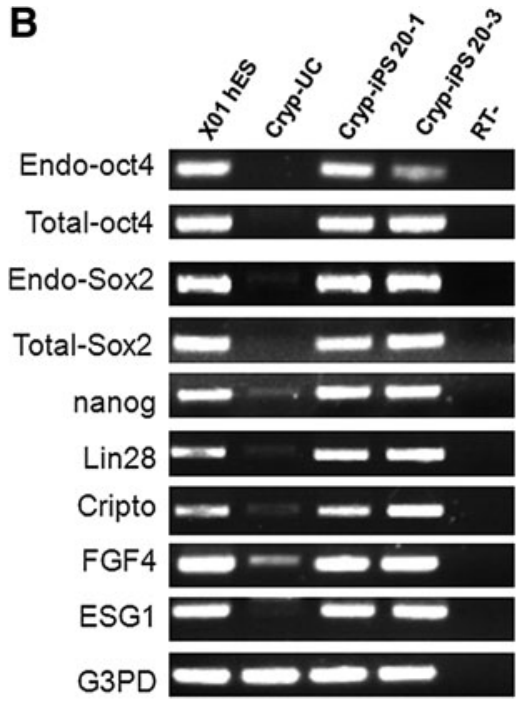

C

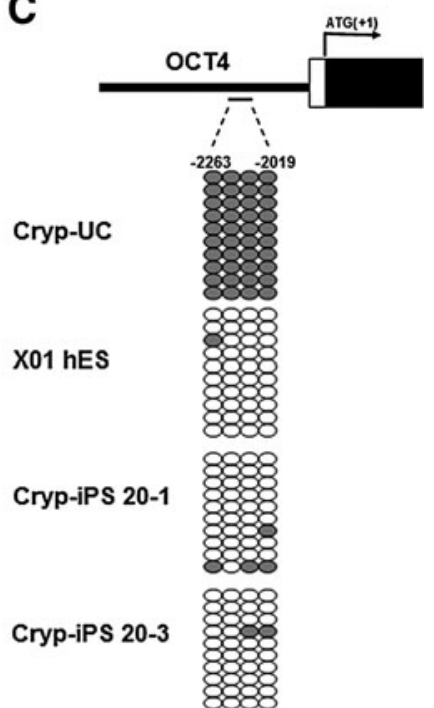

FIG. 5. Pluripotent gene expression analyses and bisulfite genomic sequencing of reprogrammed cells. (A) Quantitative reverse transcription-polymerase chain reaction analyses indicated total (dark gray bars) and endogenous (light gray bars) OCT4 and SOX2 expression in reprogrammed cells versus $\times 01$ human ES cells and parental populations. (B) Reverse transcriptionPCR analyses of endogenous OCT4, SOX2, NANOG, CRIPTO, LIN28, FGF4, and ESG1 expression in reprogrammed cells, $\times 01$ human ES cells, and the parental somatic cell populations. (C) Bisulfite genomic sequencing of human OCT4 promoter regions in $\times 01$ human ES cells, reprogrammed cells, and the parental somatic cell populations. Each horizontal row of ovals represents an individual sequencing result. Open and closed ovals indicate unmethylated and methylated CpGs, respectively.

\section{The parental urine cells and reprogrammed cells displayed the same STR loci and normal karyotypes}

The 3 cell populations studied here, the parental urine cells and the reprogrammed Cryp-iPS 20-1 and 20-3 cells, displayed the same 16 STR loci (Fig. 6), which included 13 loci (vWA, D21S11, D18S51, D5S818, D13S317, D7S820, D16S539, FGA, D3S1358, TH01, D8S1179, TPOX, and CSF1PO) from international CODIS (Combined DNA Index System, CODIS), 2 highly polymorphic loci of Chinese populations (Penta E and Penta D), and 1 sex determination locus encoding Amelogenin.

The parental urine cells and the reprogrammed Cryp-iPS 20-1 and 20-3 cells all exhibited the normal karyotype of diploid 46 XY by Giemsa banding (Fig. 6).

\section{Pluripotency of reprogrammed cells}

Teratomas were detected and harvested 8 weeks after injection into NOD-SCID mice (Fig. 7Aa). A total of 2 and 3 mice formed teratomas following injection with Cryp-iPS 20-1 and 20-3 cells, respectively. Histochemical staining indicated the existence of various tissues types, such as neural epithelia (Fig. 7Ab), cartilage (Fig. 7Ac), and intestinal epithelia (Fig. 7Ad). In addition, reprogrammed cells could also be differentiated in vitro into cell types of the 3 germ layers (Fig. 7B). When the reprogrammed cells were cultured in suspension, EBs formed (Fig. 7Ba) that expressed markers of the 3 germ layers (Fig. 7Bb). When the cells were further differentiated in adherent cultivation, they were induced into the sox1-positive neural lineage (Fig. 7Bc), the VASA-positive germ cell lineage
FIG. 6. STR and karyotype analysis of parental somatic cells and reprogrammed cells. STR analysis indicated the same loci in all 3 cell groups. After reprogramming, the cells had the normal karyotype, consistent with the parental somatic cells. STR, short tandem repeat.
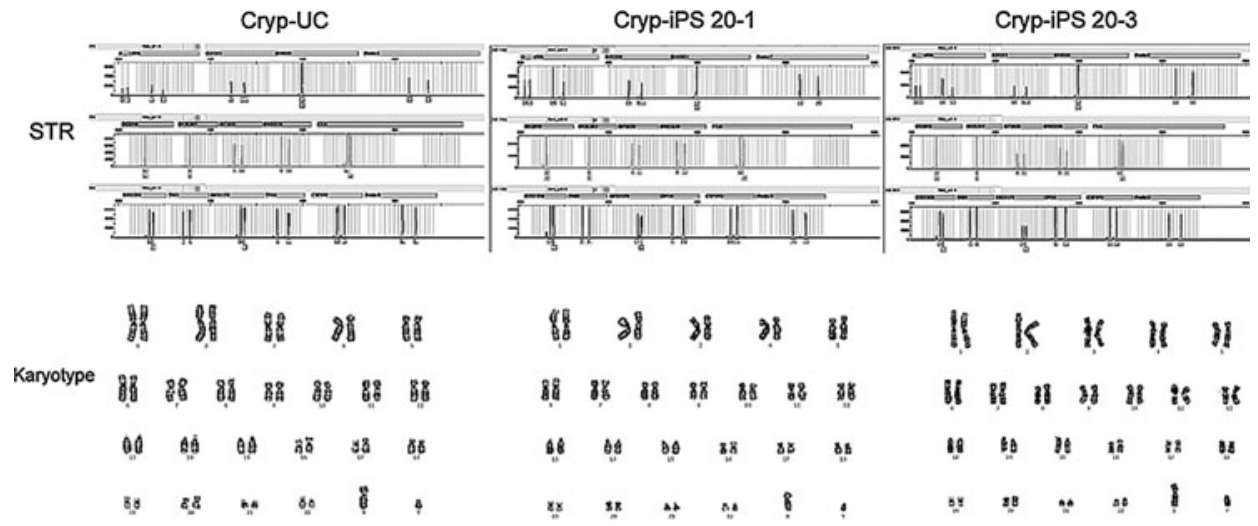

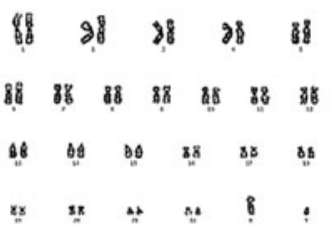

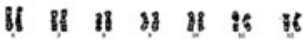

I9

$\because \quad \because \quad 8 \quad 9$
If $k$ k \|\| 

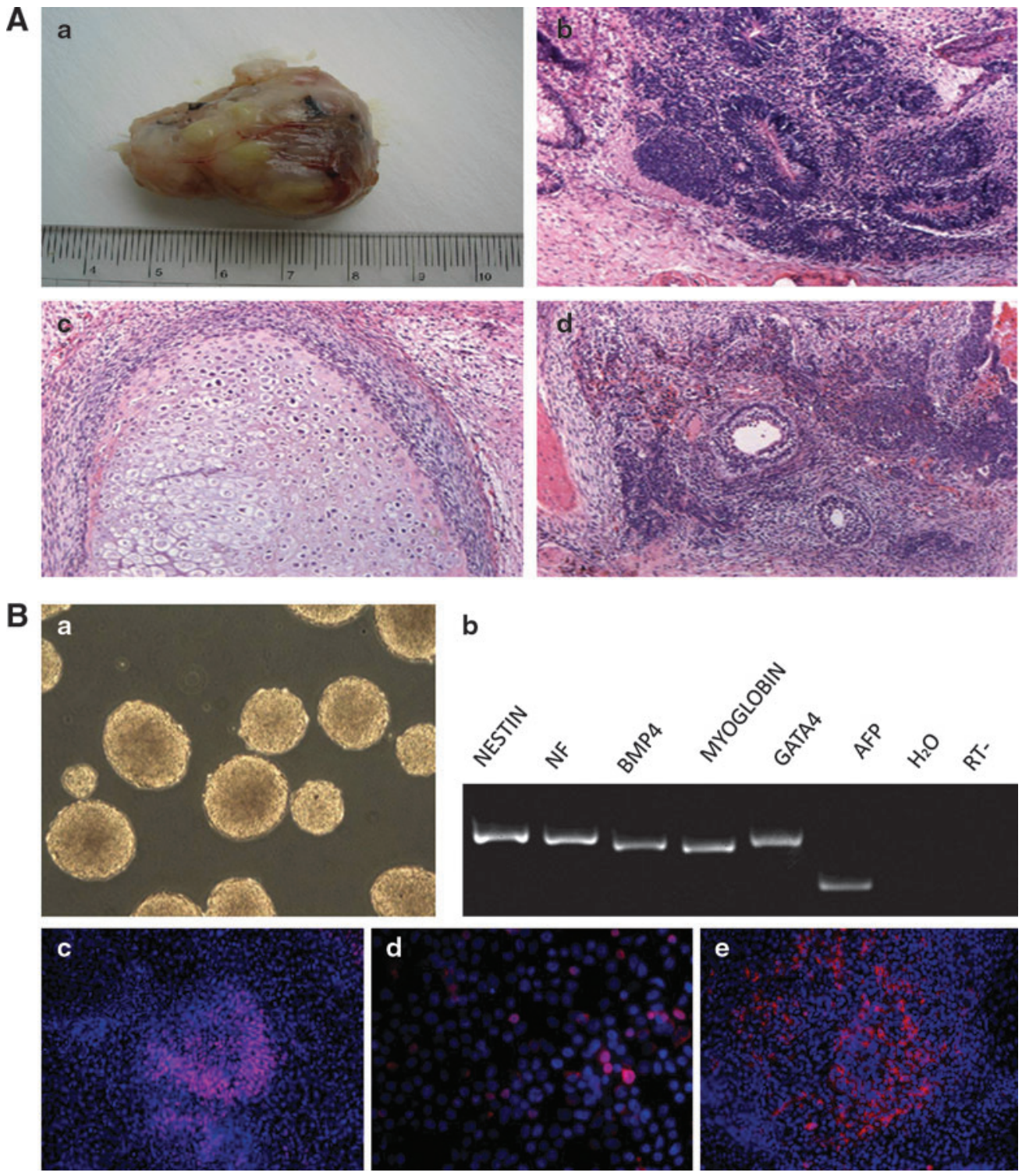

FIG. 7. In vivo and in vitro differentiation potential of reprogrammed cells. (A) In vivo differentiation potential of reprogrammed cells. The mice were euthanized when the teratoma was formed. The teratoma was photographed with a ruler (a). Hematoxylin and eosin staining of a teratoma derived from Cryp-iPS 20-1 that was composed of various tissue types: neural epithelia (b), cartilage (c), and intestinal epithelia (d). (B) In vitro differentiation potential of reprogrammed cells. EB formed on a low attachment culture dish (a). After suspension culture for 12 days, the cells expressed markers of all 3 germ layers (b). The expression of markers of different germ layers was examined using immunostaining (c-e). Magnifications were $100 \times$ for A (b, c, d) and B (a), $200 \times$ for B (c, e), and $400 \times$ for B (d).

(Fig. 7Bd), and the armor fetal protein-positive hepatic lineage (Fig. 7Be), further demonstrating their differentiation potential.

\section{Discussion}

This study demonstrated the successful establishment and characterization of the genetically mutated cryptorchidspecific iPS cell lines Cryp-iPS 20-1 and 20-3 from a noninvasive urine sample obtained from a cryptorchid patient. These cells expressed human ES cell-specific markers, demonstrated the same epigenetic status of the pluripotent cell-specific gene OCT4 as human ES cells, and exhibited the potential to differentiation along multiple lineages. These cell lines, which have the same karyotype and STR loci as their parental urine cells, could serve as an in vitro human genetic system for future research on in vivo early germ cell determination and the development of human cryptorchidism.

Although iPS cell research is plagued by issues, such as safety [11] and low efficiency, researchers have made great efforts to solve these problems. Aside from the clinical application of iPS cells, using disease-specific iPS cells to mimic the development of the corresponding disease may represent a fruitful application of this technology, especially for diseases resulting from abnormal embryonic development.

Cryptorchidism affects between $1 \%$ and $2 \%$ of the male population [3]. This disease has been regarded as an important 
cause of male infertility and presents a particular risk for bilateral cases. Although early orchidopexy can decrease the infertility resulting from cryptorchidism, satisfactory fertility cannot be achieved in all of these cases, implying that the mechanisms of this infertility need to be investigated further.

Animals are commonly used as models of human disease [12]. Models of cryptorchidism have been created by administering estrogen to pregnant mice and rats. However, these models did not contain the genetic background of cryptorchidism. In addition, there were fundamental differences between the human and model organisms. Although these models contain mutations in INSL3 and its Leu-rich repeat-containing $G$ protein-coupled receptor 8 (LGR8), homeobox A10 (HOXA10), ZNF214, and ZNF215 that have also been discovered in human tissue samples [13-15], the effects of these mutations on testis development and fertility need to be investigated in a human research model.

Human iPS cells are considered valuable research tools $[9,16,17]$. Researchers have used iPS cells as models of hematopoietic disease [18], neurogenic disease [19-21], heart disease [22], and diabetes [23]. Meanwhile, the germ cell differentiation of iPS cells has also been achieved [24-26]. All these achievements have paved the way for investigating the germ cell differentiation from cryptorchid-specific iPS cells containing the appropriate genetic background.

Skin fibroblasts have been widely used as parental cells [5-7], and we have previously established iPS cell lines from cells obtained from human amniotic fluid [27]. Both of these parental cells were obtained through invasive sample collection. In contrast, this study used urine cells obtained from totally noninvasive urine collection, which is a more suitable method of collecting pediatric samples for the investigation of pediatric diseases. Urine cells were first propagated for tissue engineering [28]. We have cultured urine cells from patients with cryptorchidism and hypospadias, and these cells mainly expressed urothelial surface markers [10]. Genetically normal urine cells and kidney mesangial cells have been successfully reprogrammed during the preparation of this manuscript [29-31]. All these results, together with our urine-derived cryptorchid-specific iPS cell lines with genetic variations, demonstrate that urine cells are one of the most acceptable noninvasive sources of iPS cells, especially for research on pediatric diseases.

This research has established cryptorchid-specific iPS cell lines with the following 2 critical advantages: first, urine cells are one of the most acceptable noninvasive sources of parental cells for the preparation of iPS cells for research on pediatric diseases; second, cryptorchid-specific iPS cells contain the appropriate genetic background, making them a unique human system for the research of cryptorchidismrelated infertility.

Based on this preliminary study, further research will be necessary to explore how the mutated genes influence the germ cell differentiation of cryptorchidism and whether targeted gene correction could rescue the function of germ cells. This possibility should be studied using a stepwise induction system rather than the spontaneous differentiation reported here. Technical improvements in reprogramming are also needed to produce clinically safe cell sources that could be applied in cellular-based therapies.

\section{Acknowledgments}

We are grateful to Dr. Jianjun Shi and Dr. Ann Griffith for their critical review of this manuscript. This research was supported by grants from the China Natural Science Foundation (81070476, 81270742), doctoral fund of Ministry of Education of China (20100073120093), Science and Technology Commission of Shanghai Municipality (10ZR1424700, 11JC1411100), program for Outstanding Medical Academic Leader of Shanghai (LJ 10016), Shanghai Municipal Health Bureau (2008054), and new 100 talented researchers of the Shanghai Jiaotong University School of Medicine.

\section{Author Disclosure Statement}

The authors indicate that no potential conflicts of interest exist.

\section{References}

1. Foresta C, D Zuccarello, A Garolla and A Ferlin. (2008). Role of hormones, genes, and environment in human cryptorchidism. Endocr Rev 29:560-580.

2. Katrine B, MM Katharina, J Jorma and NE Skakkebæk. (2011). Testicular descent: INSL3, testosterone, genes and the intrauterine milieu. Nat Rev Urol 8:187-196.

3. Hadziselimovic F. (2002). Cryptorchidism, its impact on male fertility. Eur Urol 41:121-123.

4. Clark AT and RA Reijo Pera. (2006). Modeling human germ cell development with embryonic stem cells. Regen Med 1:85-93.

5. Takahashi K and S Yamanaka. (2006). Induction of pluripotent stem cells from mouse embryonic and adult fibroblast cultures by defined factors. Cell 126:663-676.

6. Takahashi K, K Tanabe, M Ohnuki, M Narita, T Ichisaka, K Tomoda and S Yamanaka. (2007). Induction of pluripotent stem cells from adult human fibroblasts by defined factors. Cell 131:861-872.

7. Yu J, MA Vodyanik, K Smuga-Otto, J Antosiewicz-Bourget, JL Frane, S Tian, J Nie, GA Jonsdottir, V Ruotti, et al. (2007). Induced pluripotent stem cell lines derived from human somatic cells. Science 318:1917-1920.

8. Thomson JA, J Itskovitz-Eldor, SS Shapiro, MA Waknitz, JJ Swiergiel, VS Marshall and JM Jones. (1998). Embryonic stem cell lines derived from human blastocysts. Science 282:1145-1147.

9. Robinton DA and GQ Daley. (2012). The promise of induced pluripotent stem cells in research and therapy. Nature 481:295-305.

10. Zhou JM, X Wang, SL Zhang, L Yu, YJ Gu and F Chen. (2012). In vitro culture and characterization of cells derived from urine of cryptorchidism and hypospadias. Chin J Pediatr Surg 33:188-192.

11. Zhang GC, BX Shang, P Yang, ZF Cao, YY Pan and QS Zhou. (2012). Induced pluripotent stem cell consensus genes: implication for the risk of tumorigenesis and cancers in induced pluripotent stem cell therapy. Stem Cells Dev 21:955964.

12. Matzuk MM and DJ Lamb. (2008). The biology of infertility: research advances and clinical challenges. Nat Med 14:11971213.

13. Ferlin A, D Zuccarello, B Zuccarello, MR Chirico, GF Zanon, and C Foresta. (2008). Genetic alterations associated with cryptorchidism. JAMA 300:2271-2276. 
14. Massart F and G Saggese. (2010). Morphogenetic targets and genetics of undescended testis. Sex Dev 4:326-335.

15. Hadziselimovic F, NO Hadziselimovic, P Demougin and EJ Oakeley. (2011). Testicular gene expression in cryptorchid boys at risk of azoospermia. Sex Dev 5:49-59.

16. Nishikawa S, RA Goldstein and CR Nierras. (2008). The promise of human induced pluripotent stem cells for research and therapy. Nat Rev Mol Cell Biol 9:725-729.

17. Park IH, N Arora, H Huo, N Maherali, T Ahfeldt, A Shimamura, MW Lensch, C Cowan, K Hochedlinger and GQ Daley. (2008). Disease-specific induced pluripotent stem cells. Cell 134:877-886.

18. Raya A, I Rodríguez-Pizà, G Guenechea, R Vassena, S Navarro, MJ Barrero, A Consiglio, M Castellà, P Río, et al. (2009). Disease-corrected haematopoietic progenitors from fanconi anaemia induced pluripotent stem cells. Nature 460:53-59.

19. Dolmetsch R and DH Geschwind. (2011). The human brain in a dish: the promise of iPSC-derived neurons. Cell 145:831834.

20. Marchetto MC, KJ Brennand, LF Boyer and FH Gage. (2011). Induced pluripotent stem cells (iPSCs) and neurological disease modeling: progress and promises. Hum Mol Genet 20:R109-R115.

21. Ananiev G, CE Williams, HD Li and Q Chang. (2011). Isogenic pairs of wild type and mutant induced pluripotent stem cell (iPSC) lines from rett syndrome patients as in vitro disease model. PLoS One 6:e25255-e25264.

22. Moretti A, M Bellin, A Welling, CB Jung, JT Lam, L BottFlügel, T Dorn, A Goedel, C Höhnke, et al. (2010). Patientspecific induced pluripotent stem-cell models for long-QT syndrome. N Engl J Med 363:1397-1409.

23. Maehr R. (2011). iPS cells in type 1 diabetes research and treatment. Clin Pharmacol Ther 89:750-753.

24. Aflatoonian B, L Ruban, M Jones, R Aflatoonian, A Fazeli and HD Moore. (2009). In vitro post-meiotic germ cell development from human embryonic stem cells. Hum Reprod 24:3150-3159.

25. Panula S, JV Medrano, K Kee, R Bergström, HN Nguyen, B Byers, KD Wilson, JC Wu, C Simon, O Hovatta and RA Reijo Pera. (2011). Human germ cell differentiation from fetal- and adult-derived induced pluripotent stem cells. Hum Mol Genet 20:752-762.
26. Eguizabal C, N Montserrat, $\mathrm{R}$ Vassena, M Barragan, E Garreta, L Garcia-Quevedo, F Vidal, A Giorgetti, A Veiga and JC Izpisua Belmonte. (2011). Complete meiosis from human induced pluripotent stem cells. Stem Cell 29:11861195.

27. Li C, J Zhou, G Shi, Y Ma, Y Yang, J Gu, H Yu, S Jin, Z Wei, F Chen and Y Jin. (2009). Pluripotency can be rapidly and efficiently induced in human amniotic fluid-derived cells. Hum Mol Genet 18:4340-4349.

28. Zhang Y, E McNeill, H Tian, S Soker, KE Andersson, JJ Yoo and A Atala. (2008). Urine derived cells are a potential source for urological tissue reconstruction. J Urol 180:22262233.

29. Song B, JC Niclis, MA Alikhan, S Sakkal, A Sylvain, PG Kerr, AL Laslett, CA Bernard and SD Ricardo. (2011). Generation of induced pluripotent stem cells from human kidney mesangial cells. J Am Soc Nephrol 22:1213-1220.

30. Zhou T, C Benda, S Duzinger, Y Huang, X Li, Y Li, X Guo, G Cao, S Chen, et al. (2011). Generation of induced pluripotent stem cells from urine. J Am Soc Nephrol 22:1221-1228.

31. Montserrat N, MJ Ramirez-Bajo, Y Xia, I Sancho-Martinez, D Moya-Rull, L Miquel-Serra, S Yang, E Nivet, C Cortina, et al. (2012). Generation of induced pluripotent stem cells from human renal proximal tubular cells with only two transcription factors: OCT4 and SOX2. J Biol Chem 287:2413124138.

Address correspondence to: Dr. Fang Chen

Department of Urology Children's Hospital of Shanghai Shanghai Jiaotong University 1400 Beijing Road West Jingan District Shanghai 200040

China

E-mail: cdbxh@yahoo.cn; chenfang007@hotmail.com

Received for publication May 26, 2012 Accepted after revision October 1, 2012

Prepublished on Liebert Instant Online October 1, 2012 